\title{
Biologically-derived neoproteoglycans for profiling protein-glycosaminoglycan interactions
}

Ryan N. Porell, ${ }^{1}$ Julianna L. Follmar, ${ }^{1}$ Sean C. Purcell, ${ }^{1}$ Bryce Timm,${ }^{1}$ Logan K. Laubach, ${ }^{1}$ David Kozirovskiy, ${ }^{1}$ Bryan E. Thacker, ${ }^{4}$ Charles A. Glass, ${ }^{4}$ Philip L. S. M. Gordts, ${ }^{2,3}$ Kamil Godula ${ }^{1,3 *}$

${ }^{1}$ Department of Chemistry and Biochemistry, ${ }^{2}$ Department of Medicine, ${ }^{3}$ Glycobiology Research and Training Center, University of California, San Diego, La Jolla, CA 92093, USA.

${ }^{4}$ TEGA Therapeutics, Inc., 3550 General Atomics Court, G02-102, San Diego, CA 92121, USA.

Author contributions: R.N.P., K.G., and P.L.S.M.G. conceived, initiated, and coordinated the project. R.N.P., J.L.F, L.L., S.P., B.M.T., D.K., and B.E.T. designed and performed the experimental work. B.E.T. and C.A.G. generated bioengineered rHS. R.N.P., J.L.F, and K.G. wrote the manuscript. All authors discussed the experiments and results, read, and approved the manuscript.

*To whom correspondence should be addressed: Kamil Godula: Department of Chemistry and Biochemistry, University of California San Diego, 9500 Gilman Drive, MC 0358 La Jolla, CA, USA. E-mail: kgodula@ucsd.edu 


\section{Graphical Abstract}

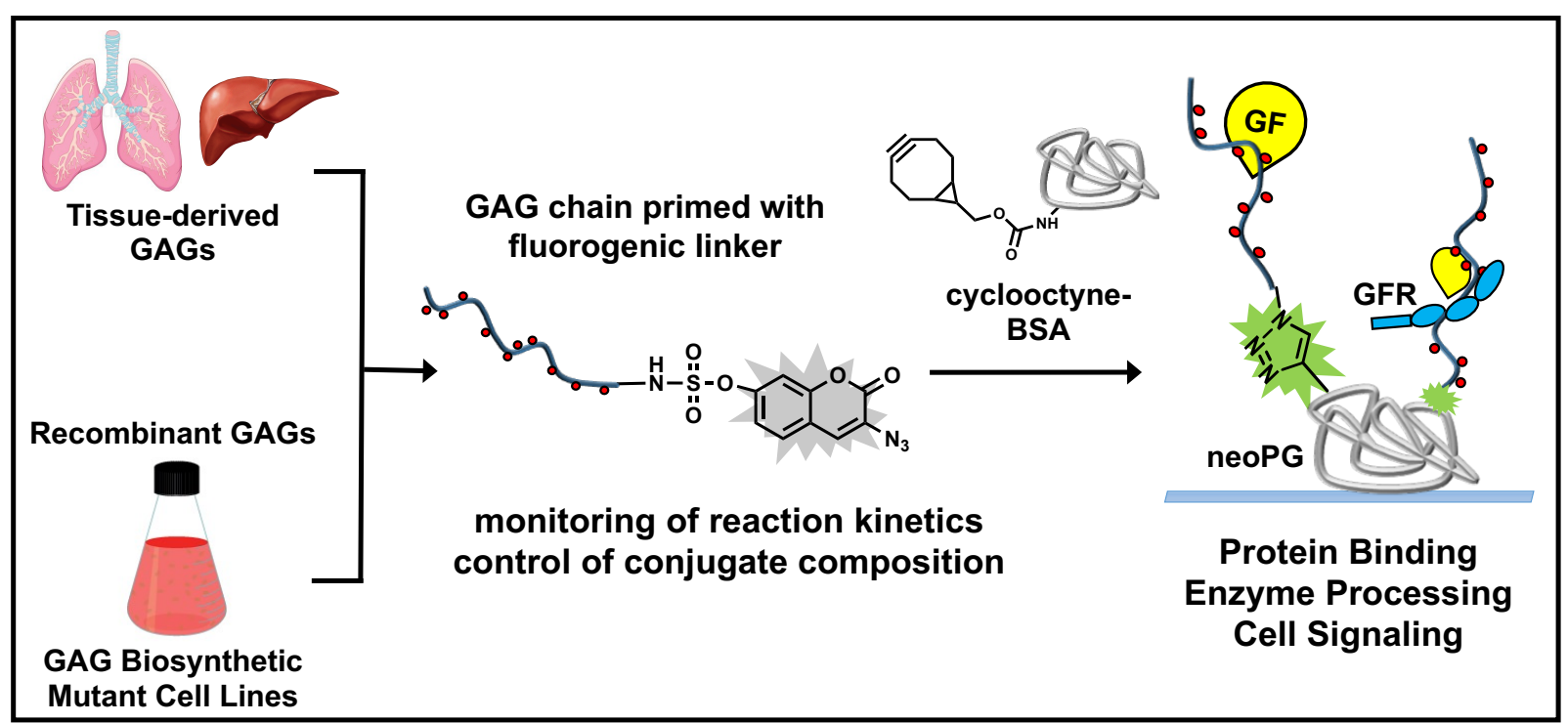

\section{Abstract}

Glycosaminoglycans (GAGs) are a class of highly negatively charged membrane associated and extracellular matrix polysaccharides involved in the regulation of myriad biological functions, including cell adhesion, migration, signaling and differentiation, among others. GAGs are typically attached to core proteins, termed proteoglycans (PGs), and can engage $>500$ binding proteins, making them prominent relays for sensing external stimuli and transducing cellular responses. However, their unique substructural protein-recognition domains that confer their binding specificity remain elusive. While the emergence of glycan arrays has rapidly enabled the profiling of ligand specificities of a range of glycan-binding proteins, their adaptation for the analysis of GAG-binding proteins has been considerably more challenging. Current GAGmicroarrays primarily employ synthetically defined oligosaccharides, which capture only a fraction of the structural diversity of native GAG polysaccharides. Augmenting existing array platforms to include GAG structures purified from tissues or produced in cells with engineered glycan biosynthetic pathways may significantly advance the understanding of structure-activity relationships in GAG-protein interactions. Here, we demonstrate an efficient and tunable strategy 
to mimic cellular proteoglycan architectures by conjugating biologically-derived GAG chains to a protein scaffold, defined as neoproteoglycans (neoPGs). The use of a reactive fluorogenic linker enabled real-time monitoring of the conjugation reaction efficiency and tuning of the neoPG valency. Immobilization of the reagents on a 96-well array platform allowed for efficient probing of ligand binding and enzyme substrate specificity, including growth factors and the human sulfatase 1. The neoPGs can also be used directly as soluble probes to evaluate GAG-dependent growth factor signaling in cells.

\section{Introduction}

Proteoglycans (PGs) are abundant on cell surfaces and in the extracellular matrix, where they serve a myriad of biological functions spanning from regulation of growth factor binding and signaling ${ }^{1,2,3}$ to tissue development and organ function. ${ }^{4,5}$ They also contribute to pathophysiological processes, including aging and associated disease, ${ }^{6}$ immunological responses, ${ }^{7,8}$ and they serve as receptors for infectious agents, such as the Herpes simplex viruses $^{9}$ and the SARS-CoV-2 virus, ${ }^{10}$ among others. Key structural components of PGs, which define their interactions with other proteins, are sulfated glycosaminoglycan (GAG) polysaccharide chains appended to the protein core via a glycosidic bond to serine and threonine residues. Sulfated GAGs can be classified according to their monosaccharide composition as heparan sulfate (HS), chondroitin sulfate (CS), dermatan sulfate (DS), and keratan sulfate (KS). Hyaluronan (HA), which is the last member of the GAG family, lacks sulfation and is not attached to proteins (Figure 1). 


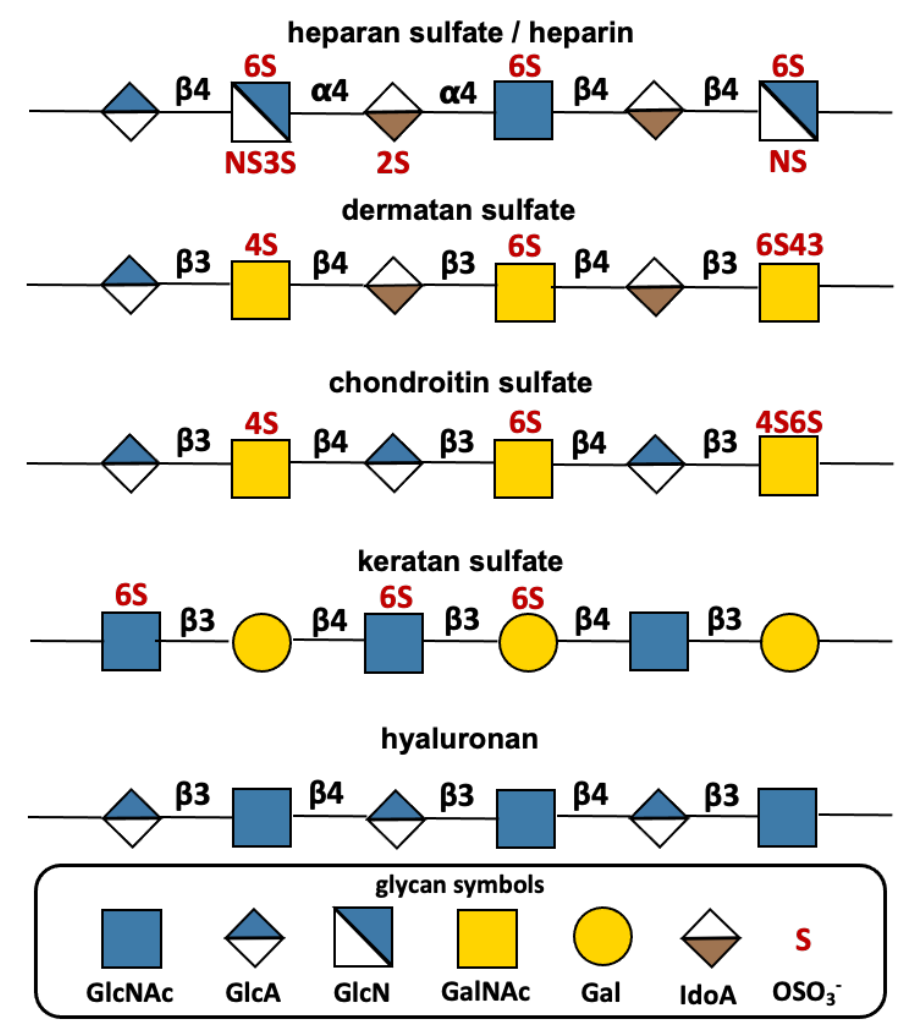

Figure 1: Common structures of GAGs using the glycan symbol nomenclature. Possible sulfation sites are displayed in red text above or below their respective monosaccharide.

The biological specificity of GAGs is established during their biosynthesis through a nontemplated process via a sequence of enzymatic modifications, which elongate the individual polysaccharide chains and install negatively charged sulfate groups. This results in structurally complex sulfation patterns organized in domains along the polysaccharides that provide highaffinity binding sites for proteins. ${ }^{11,12}$ The structure-function relationships for GAGs remain poorly defined, due to challenges in isolation and structural characterization of GAGs from biological samples, as well as difficulties with producing structurally defined GAG polysaccharides synthetically.

Since their inception in $2002,{ }^{13,14,15}$ glycan arrays have become broadly adapted as a high throughput glycomics tool to profile ligand specificity of glycan binding proteins. ${ }^{16}$ The glycan array developed by the National Center for Functional Glycomics ${ }^{17}$ now contains more than 1,000 
unique structures representing $\mathrm{N}$ - and $\mathrm{O}$-linked glycans and is considered the gold standard for the field. Parallel pioneering efforts to establish GAG arrays using synthetic $\mathrm{HS}^{18}$ and $\mathrm{CS}^{19}$ oligosaccharides provided early insights into GAG structure-function relationships. Advances in chemoenzymatic synthesis of GAG oligosaccharides have significantly accelerated these efforts in recent years..$^{20,21,22}$ Upwards of 95 synthetic HS structures are now available in an array format, ${ }^{23}$ which is still a significant shortfall from the total amount of GAG structures that are found naturally.

Complementing bottom-up synthetic efforts are arrays consisting of biologically-derived GAGs representing the structural complexity of the natural polysaccharides, however, these efforts faced major roadblocks due to difficulties in purification and separation of GAGs into structurally distinct populations. ${ }^{24}$ Recent advances in generating glycosylation mutant cell lines through systematic genetic manipulation of GAG biosynthesis are alleviating this limitation by providing access to increased quantities of compositionally-defined bioengineered GAGs. ${ }^{25,26}$

A technical challenge in generating native and bioengineered GAG arrays is the optimization of GAG immobilization onto surfaces. Commonly employed approaches include electrostatic adsorption of the polyanionic glycans onto positively charged poly(lysine)-coated surfaces ${ }^{27}$ or precipitation on plastic supports using ammonium chloride. ${ }^{28}$ These methods unequally sequester biologically active sulfated domains and influence protein binding. Alternatively, covalent conjugation of GAGs via their reducing ends to amine-, aminooxy-, or hydrazine-functionalized surfaces allows for glycan extension away from the surface, enhancing chain presentation. ${ }^{29,30}$ However, chain grafting efficiency is generally low and varies based on the length and charge of the GAG structure. The inability to characterize the GAGs presentations after immobilization introduces a degree of uncertainty making it difficult to perform comparative analysis of protein binding specificity.

Here, we introduce semi-synthetic neoproteoglycan (neoPG) reagents with a defined molecular architecture to permit comparative analysis of GAG-protein binding interactions. The 
neoPG has GAG polysaccharides chains end-conjugated to a carrier bovine serum albumin (BSA) protein, improving on existing reductive amination protocols. ${ }^{31}$ We employ the strain-promoted alkyne-azide cycloaddition (SPAAC) reaction ${ }^{32}$ with a reactive fluorogenic linker to generate the glycoconjugates. The strategy enables efficient coupling with real-time monitoring of GAG conjugation and quantification of the neoPG composition. This novel method is suitable for all members of the GAG family, including tissue-derived and bioengineered polysaccharides and the reagents can be immobilized in an ELISA format to analyze GAG-binding protein interactions or used as soluble reagents to evaluate signaling activity in cells.

\section{Results and Discussion}

Generation of neoProteoglycans (neoPGs). To generate versatile reagents suitable for analysis of GAG-interactions in analytical assays as well as biological assays, we developed a chemical approach for merging polysaccharides with a protein carrier without disrupting ligandbinding domains. Covalent GAG attachment to the protein backbone mimics the organization of native PGs and provides control over GAG valency and presentation both in solution and after immobilization on surfaces. However, macromolecular assemblies of the highly sulfated GAG polysaccharides with other macromolecules, including proteins, necessitates efficient and highyielding bioconjugation chemistries. This is particularly challenging for conjugation of GAGs from biological samples, which can only be isolated in limited amounts or otherwise become costly.

To address these challenges, we have developed a fluorogenic bioorthogonal linker strategy for attaching GAG chains through their reducing ends to a BSA protein carrier. In this process, the GAG chains are furnished with a novel azido-coumarin linker that produces fluorescent light emission $\left(\lambda_{\text {ex/em }}=393 / 477 \mathrm{~nm}\right.$ ) upon further conjugation with alkynes. This strategy enables direct monitoring and quantification of the coupling reaction (Figure $2 \mathrm{~b}$ ). The 
linker is introduced via the sulfur (IV) fluoride exchange (SufEx) ${ }^{33}$ reaction between 3azidocoumarin-7-sulfonyl fluoride (ACS-F) and amine-terminated GAG chains. The amine groups either originate from amino acid residues retained after GAG release from proteoglycans by pronase digestion or are introduced quantitatively to the hemiacetal end of $\beta$-eliminated chains by treatment with $\mathrm{N}$-methylaminooxy propylamine (Figure S6). ${ }^{3435}$ After removal of excess ACSF linker by size exclusion chromatography and dialysis, the chemically primed GAGs (ACSGAGs) were conjugated to a bicyclo[6.1.0]nonyne-modified BSA protein (BCN-BSA) via the strain-promoted azide-alkyne cycloaddition (SPAAC) $)^{36}$ to generate neoPGs (Figure 2a). Fluorescence readout from the fluorogenic linker provided conjugation kinetics and stoichiometry of the resulting neoPGs, which was confirmed through a combination of BCA and carbazole assays to determine the respective BSA and GAG content after removal of unreacted GAG chains by dialysis. The fluorescence from triazole-coumarin sulfonyl-BSA (TCS-BSA) conjugate produced by reacting BCN-BSA with the ACS-F linker alone was used to calibrate the measurement and to establish the maximal number of conjugation sites ( $\sim 16$ cyclooctynes per BSA, Figure S5) on the protein (Figure 2b). Using this approach, we prepared neoPG conjugates using polysaccharides representing the main classes of GAGs. These included commercially available heparin (Hep, a highly sulfated form of HS), HA, and bovine cartilage CS as well as HS, CS and KS isolated from pig lung and mouse liver tissues (Table S2). Under optimized conditions, BCN-BSA ( 1 nM) was reacted with ACS-GAGs ( 10 equiv. per BSA) in PBS buffer at ambient temperature for $20 \mathrm{hrs}$. Each neoPG was assigned a descriptor $\mathbf{G A G}_{\mathbf{x}}-\mathbf{B S A}$, where $\mathrm{x}$ designates the number of GAG chains per BSA molecule. The conjugation process was efficient, and the maximum number of GAG chains introduced into the neoPGs ranged from $\mathrm{x} \sim 6-8$ for $\mathrm{HS}$, KS and $\mathrm{HA}$ and $\mathrm{x} \sim 8-12$ for CS. Both the size and charge of the polysaccharides likely contribute to the overall efficiency of the conjugation process; however, we did not observe any noticeable trends (Figure 2c and Table S2). The composition of the conjugates with respect to GAG chain valency can be tuned by controlling the reagent stoichiometry or reaction time. 
a

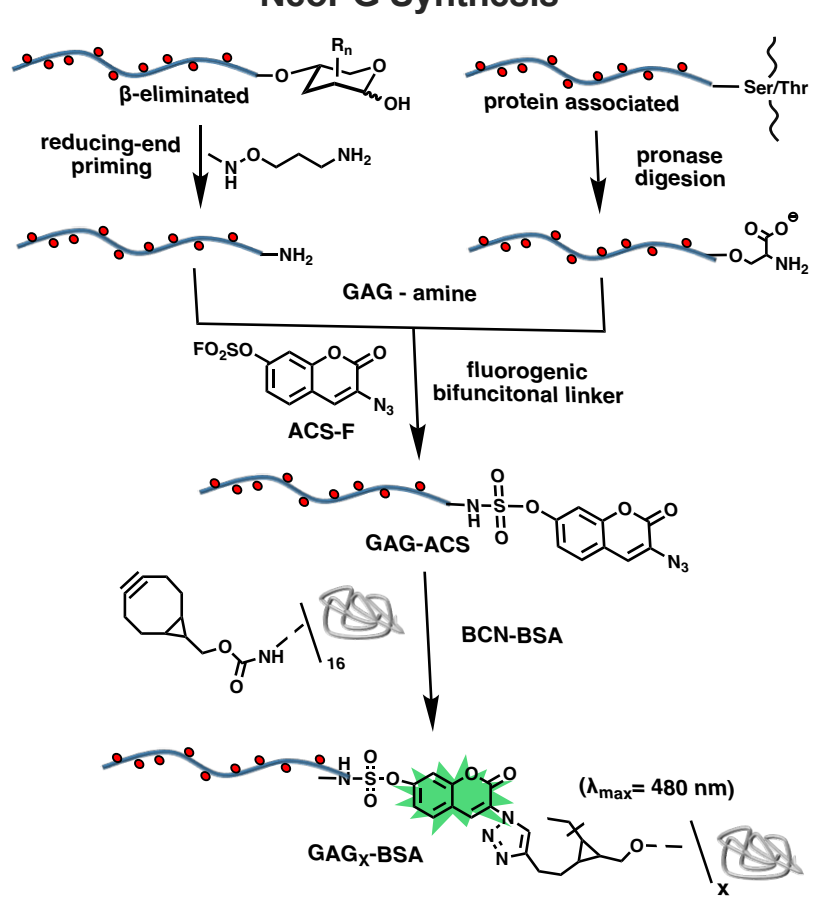

b

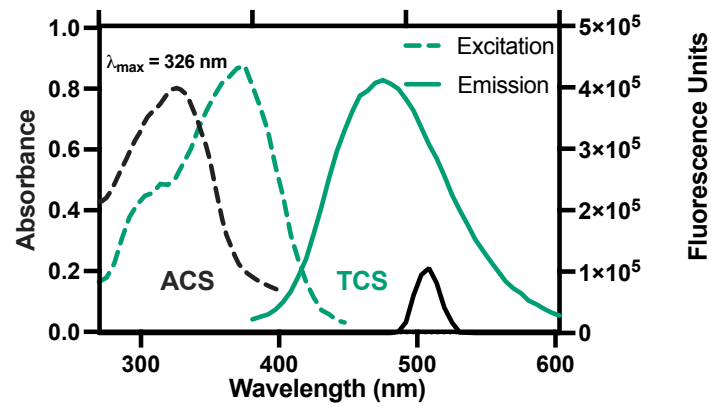

C

Conjugation Kinetics

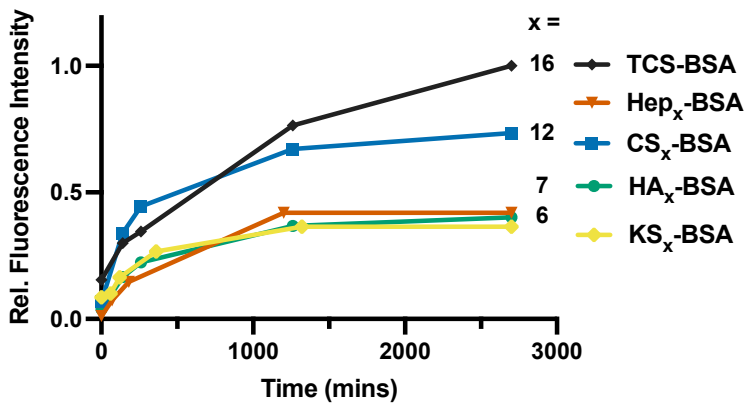

Figure 2: Preparation of HS, CS, KS, \& HA neoPGs. a) Workflow for neoPG synthesis using recombinant or tissue purified GAGs. Fluorogenic bifunctional azidocoumarin sulfonyl fluoride (ACS-F) linker was conjugated via the sulfur (IV) fluoride exchange reaction to GAG chains primed at their reducing end with reactive amines. Subsequent strain-promoted azide-alkyne cycloaddition (SPAAC) reaction with cyclooctyne-functionalized BSA (BCN-BSA) furnished the desired neoPGs. Fluorescence signal produced upon conversion of the ACS handle into triozolylcoumarin sulfonamide (TCS) was used to monitor the progress of the conjugation reaction. b) Absorbance (dashed) and fluorescence (solid) spectra of quenched ACS-F (black) and unquenched TCS-BSA (green). c) Fluorescence emission (393 nm Ex./477 nm Em.) was used to monitor conjugation kinetics for Hep (red), CS (blue), HA (green), and KS (yellow) neoPGs. GAG chain valency of the resulting neoPGs was determined using TCS-BSA (black) as a standard.

NeoPGs allow for controlled surface GAG displays. The neoPG reagents can be readily immobilized onto high-binding 96-well microtiter plates through adsorption via their BSA protein core (Figure 3). The density of the immobilized GAG chains defines the avidity of the protein interactions with the surface. Accordingly, this was reflected in the binding response for the fibroblast growth factor 1 (FGF1), a well characterized HS-binding growth factor, to plates treated 
with increasing concentrations of Hep $_{7}-\mathbf{B S A}$ (20-500 ng/well, Figure 3a). Likewise, the valency of the neoPG conjugates can influence the avidity of protein binding. By controlling the Hep-ACS to BCN-BSA ratio during the conjugation reaction, we prepared neoPG conjugates displaying 1, 2 or 4 Hep chains. The valency-variant Hep - -BSA neoPGs were arrayed on plates at sub-saturation concentration (100 ng/well, Figure 3a) and probed for binding of FGF1. When normalized to BSA concentration, we observed increasing FGF1 binding reflective of the overall amount of heparin introduced to each well (Figure 3b, blue bars). When analyzed based on Hep concentration we observed a significant improvement in FGF1 binding between the monovalent and divalent neoPGs, Hep ${ }_{1}$-BSA and Hep $_{2}$-BSA, with no further increase in avidity for the tetravalent neoPG, Hep $_{4}$-BSA (Figure 3b, green bars).

To confirm that the neoPG conjugates retained the protein binding specificities of their parent GAGs after immobilization, we arrayed $\mathbf{H e p}_{\mathbf{x}^{-}}, \mathbf{C S}_{\mathbf{x}^{-}}, \mathbf{K S}_{\mathbf{x}^{-}}$, and $\mathbf{H} \mathbf{A}_{\mathbf{x}}-\mathbf{B S A}$ (100 ng/well) and tested them with proteins and antibodies with known binding activities against these GAGs, i.e., FGF2, CS-56, 5D4 and CD44, respectively (Figure 3c). Degradation of the GAG chains with HS-, CS-, KS- and HA-specific glycosidase enzymes reduced the binding of these proteins to the neoPGs, further confirming glycan-dependent interactions. The immobilization of neoPGs through their core BSA proteins thus allows for controlled presentation of GAG chains with respect to valency and surface density to evaluate protein binding and in a format accessible to GAG-processing enzymes. 

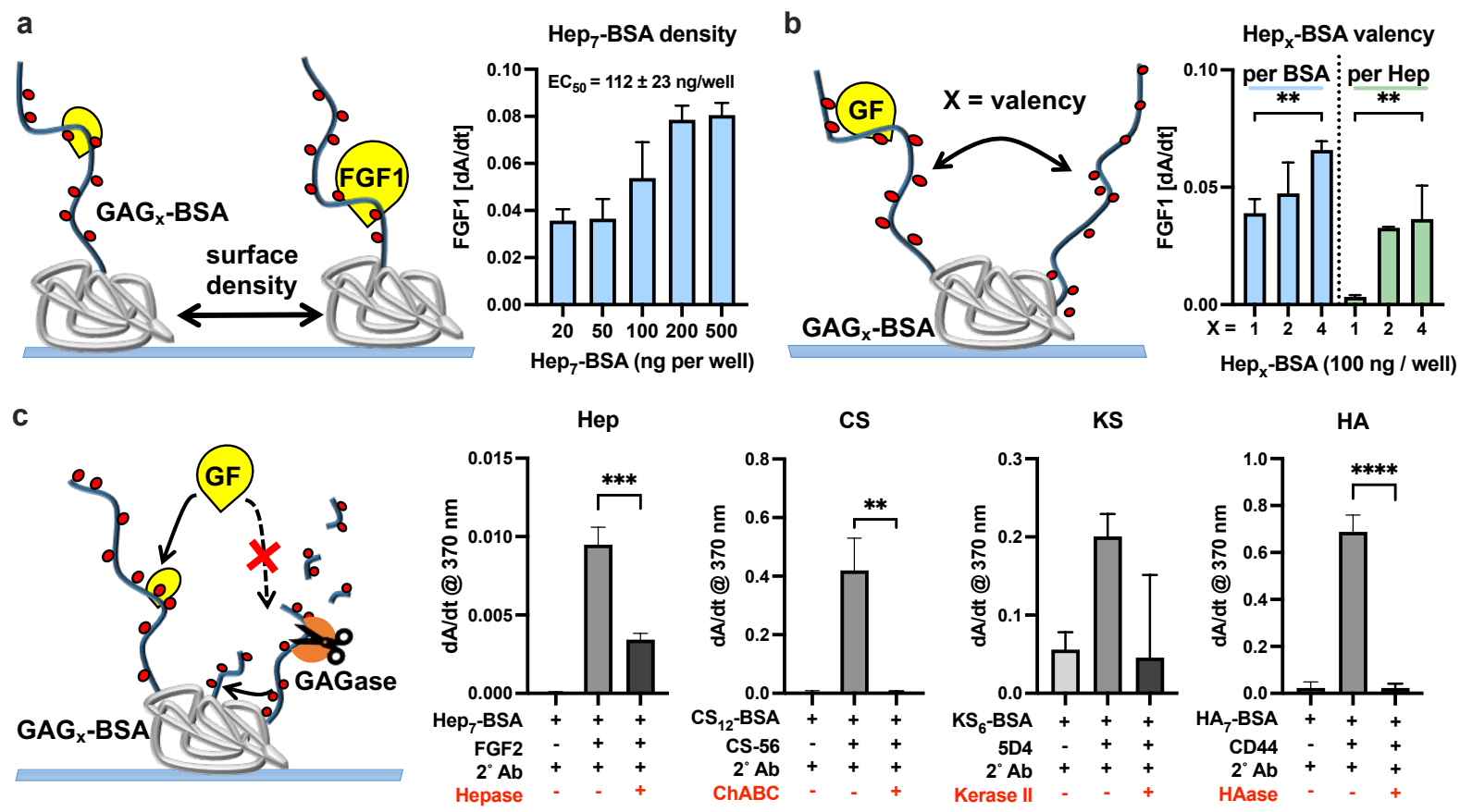

Figure 3: Construction and validation of neoPG arrays in ELISA format. a) FGF1 binding response to increasing surface density of Hep $_{7}$-BSA. b) FGF1 binding response to increasing Hep-BSA valency normalized to BSA (blue bars) and heparin (green bars) concentration. c) Effects of neoPG degradation by specific GAG-lyases (red) on protein binding. Hep 7 -BSA treated with heparin lyases and probed for FGF2 binding. CS $_{12}$-BSA treated with chondroitinase ABC and probed for CS-56 antibody binding. $\mathbf{K S}_{6}$-BSA treated with keratanase II and probed for 5D4 antibody binding. $\mathbf{H A}_{7}-\mathbf{B S A}$ treated with hyaluronidase and probed for CD44 binding. (Bar graphs represent $\mathrm{n}=3$ replicates, $p$-values were determined using student's t-test, ${ }^{* *} p<0.01,{ }^{* * *} p<$ $\left.0.001,{ }^{* * *} p<0.001,\right)$.

\section{Bioengineered recombinant HS neoPG arrays to analyze GF binding and sulfatase activity.}

Recent progress in systematic genetic manipulation of cellular HS biosynthesis has provided access to cell lines producing recombinant HS (rHS) structures with differences in overall level, type, and organization of sulfation (Figure 4a). These reagents can provide new insights into the structure-activity relationships in GAG-protein interactions and help define the substrate specificities of GAG-processing enzymes. Using our optimized conjugation method, we have converted a set of rHS polysaccharides produced in genetically engineered Chinese Hamster Ovary $(\mathrm{CHO})$ cells and mastocytoma cells ${ }^{37}$ into neoPGs. All conjugates were prepared using the 
same rHS-ACS to BCN-BSA stoichiometry $(20: 1)$ and the reactions were perfomed for $48 \mathrm{hrs}$ to maximize the extent of conjugation. The resulting neoPG conjguates were purified by dialysis to remove unreacted rHS-ACS and their valencies were determined by fluorescence reading (Figure S9). The panel of bioengineered neoPGs included rHS structures with overall sulfation levels similar to those found in native HS on cell surfaces and in tissues (i.e., rHS01, rHS02 and rHS08, Figure 4a). Compared to rHS01, the rHS02 lacked 2-O-sulfation, while rHS08 presented additional 3-O-sulfation. Also included were highly sulfated structures rHS09 and rHS29, which are similar to heparin but differed in their level of 2-O-sulfation and both lacked 3-O-sulfation (Figure 4a).

Surface density of GAG chains determines the avidity of their protein interactions and can influence binding analysis. Hence, we set to determine whether the immobilization efficiency of neoPGs was impacted by the structure and valency of their pendant rHS chains. First, we quantified the surface density of unconjugated BSA and Hep - BSA by taking advantage of the remaining unreacted cyclooctynes present on the protein. The molecules were adsorbed on plates $\left(100 \mathrm{ng} /\right.$ well) in the presence of biotin-PEG ${ }_{11}$-azide to allow for quantification of their surface density via streptavidin-HRP ELISA (Figure 4b). Treating BCN-BSA and Hep 7 -BSA with increasing amounts of the biotinylating agent, we determined that equimolar quantity of biotinPEG $_{11}$-azide per total cyclooctyne in BCN-BSA (i.e., 16 equiv.) provided maximal labeling of both conjugates after immobilization (Figure S8). Analysis of all neoPGs using half the maximal amount of biotin-PEG ${ }_{11}$-azide to account for rHS attachment and provide equal labeling of all neoPG conjugates, showed uniform surface immobilization regardless of glycosylation status (Figure 4b). The uniform neoPG adsorption on the plate surface thus allows for direct comparison of their protein binding activities.

Growth factors and morphogens commonly engage GAGs and many are well known HSbinding proteins, though the structural basis for their recognition of HS remains elusive. We assessed the binding activity of the rHS neoPGs for established HS binding proteins (Figure 4c), 
including fibroblast growth factors 1 and 2 (FGF1, FGF2), bone morphogenic proteins 2 and 4 (BMP2, BMP4), and vascular endothelial growth factor a (VEGFA). It is known that FGF1 and FGF2 require 2-O sulfate on the iduronic acid (IdoA2S) residues in HS for binding. ${ }^{38}$ Accordingly, we observed preference for FGF1 and FGF2 binding to rHS016-BSA (containing IdoA2S) over rHS02 ${ }_{10}$-BSA (lacking 2-O-sulfates). The higher valency and overall charge of rHS02 ${ }_{10}$-BSA did not compensate for the lack of 2-O sulfation.

We observed similar BMP2 binding profiles to what has been identified in current literature. ${ }^{39}$ Structures with reduced $\mathrm{N}$-sulfation ( $\mathrm{rHS01}_{6}$-BSA) present significantly diminished binding, which may be compensated for by increasing the rHS chain length and neoPG valency (rHS02 ${ }_{10}-\mathbf{B S A}$, $\sim 40 \mathrm{kDa}$ for rHS02 vs $\sim 20 \mathrm{kDa}$ vs for rHS01). While reduced sulfation levels in rHS01 $_{6}$-BSA and rHS02 10 -BSA reduced BMP4 binding, the presence of 3-O-sulfation in rHS08 restored BMP4 binding. For VEGFA, literature reports indicate a preference for disaccharides composed of iduronic acid and displaying 6-O-sulfation and $\mathrm{N}$-sulfation with no consensus on the requirement for 2-O-sulfation or 3-O-sulfation. ${ }^{40}$ We observed strongest binding of VEGFA to rHS08$_{6}$-BSA and weakest binding to $\mathrm{rHS01}_{6}$-BSA and rHS02 $_{10}$-BSA, which are similar based on quantitative levels

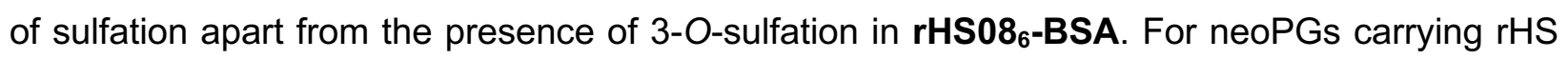

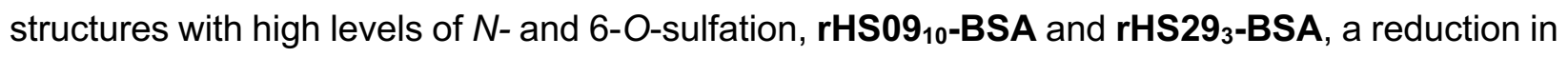
2-O-sulfation and chain valency in the latter significantly decreased VEGFA binding.

Cell surface HS can also facilitate functional pairing of GFs with their cognate receptors. To assess the ability of the immobilized neoPGs to promote the formation of ternary GAG-GFreceptor complexes, we incubated recombinantly expressed ectodomains of FGF receptors

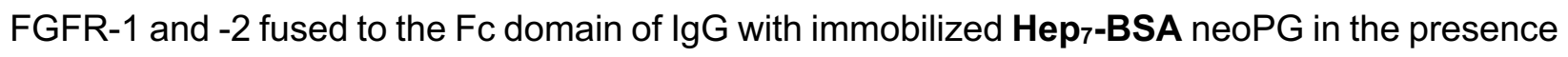
or absence of FGF1 (Figure 4d). FGFR-1 and -2 binding, detected using an anti-Fc antibody, only occurred in the presence of FGF1, indicating the formation of a ternary complex.

The neoPG array platform can also be used to analyze the interactions of GAG-modifying enzymes, such as the extracellular human 6-O-endosulfatase 1 (HSulf-1), with their substrates. 
HSulf-1 selectively cleaves 6-O-sulfates on cell-surface and ECM HSPGs and alters their GF binding activity; ${ }^{41,42,43,44}$ however, the substrate specificity of this enzyme is still poorly defined. ${ }^{45}$

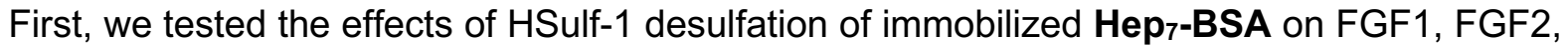
or VEGFA binding, which were selected based on their differential sensitivity to HSulf-1 activity. ${ }^{46}$ We observed significant loss of FGF1 and VEGFA binding but no significant change for FGF2 (Figure 4e), matching their known HS-binding dependence and independence on 6-O-sulfation of HS. ${ }^{38,40}$ Next, we investigated the effect of rHS composition on HSulf-1 activity and FGF1 binding (Figure 4e). We observed little change in FGF1 binding after HSulf-1 processing of rHS01 and rHS02 in their respective neoPGs, consistent with their overall low level of 6-O-sulfation. Notably, conjugate rHS08 ${ }_{6}$-BSA which also features low overall 6-O-sulfation still exhibits reduced FGF1 binding. rHS08 specifically contains the 3-O-sulfation motif, which engendered the strongest binding by FGF1, and the strongest response to HSulf-1 activity. The neoPG reagents thus provide suitable probes for characterizing the substrate specificity of the HSulfs and their dynamic regulation HS interactions with signaling proteins. 

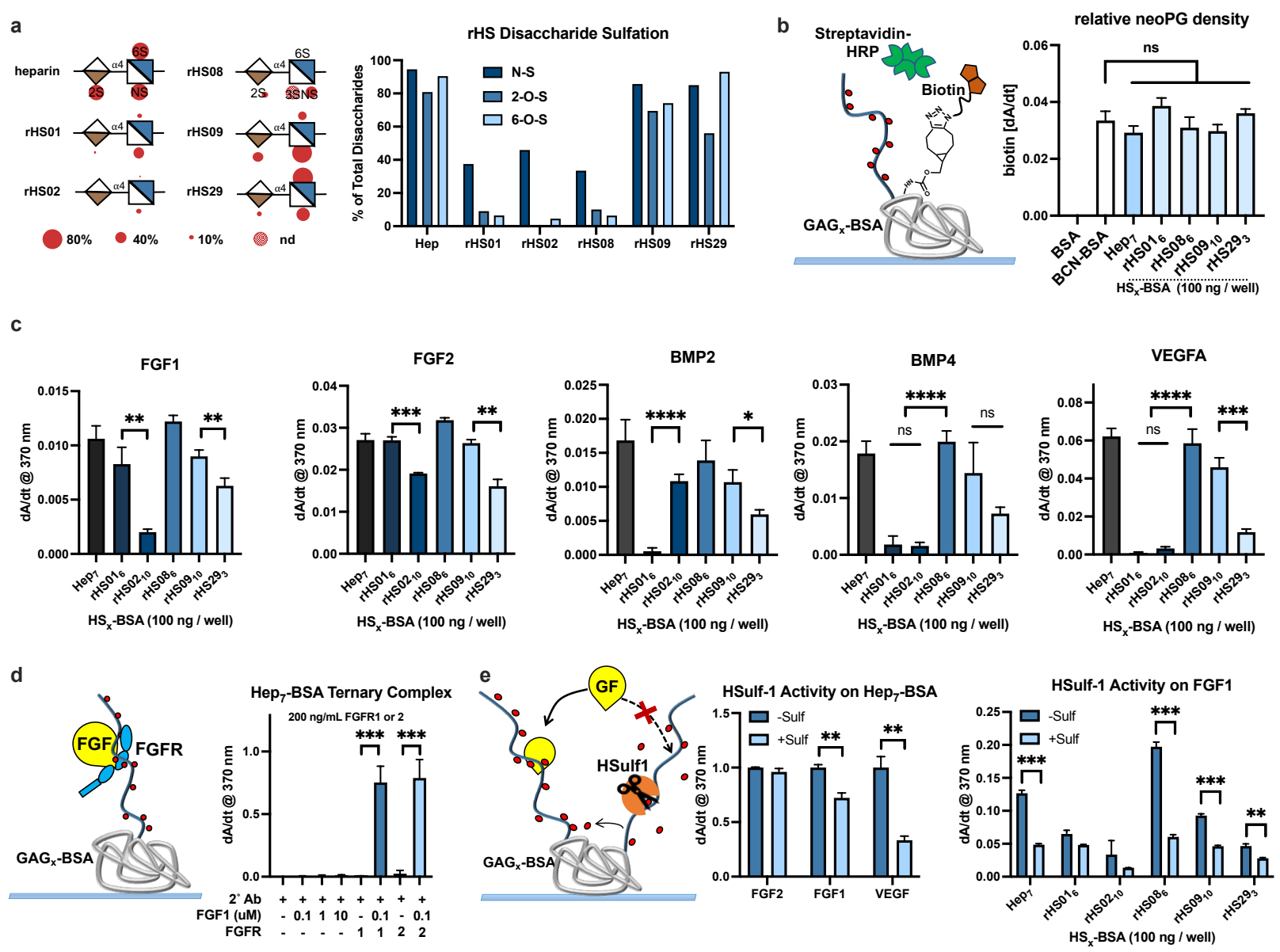

Figure 4: Analysis of protein interactions with rHS neoPGs via ELISA. a) Disaccharide composition of bioengineered rHS chains and percent site-specific disaccharide sulfation. b) Relative surface densities of rHS neoPGs after immobilization (100 ng/well) were determined via biotin-azide streptavidin-HRP assay. c) FGF1, FGF2, BMP2, BMP4, and VEGFA binding to rHS neoPGs immobilized at $100 \mathrm{ng} /$ well. d) Ternary complex formation between FGF1 and FGFR1 or

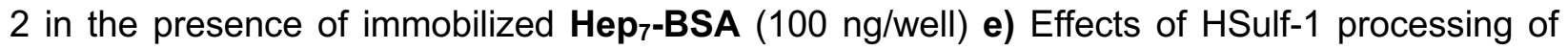
immobilized Hep $_{7}$-BSA on FGF2, FGF1, or VEGFA binding (left). Differential processing of rHS neoPGs by HSulf-1 was assessed by FGF1 binding (right). (Bar graphs represent $n=3$ replicates, $p$-values were determined using student's t-test, ${ }^{* *} p<0.01,{ }^{* * *} p<0.001,{ }^{* * *} p<0.001$,).

Activity of neoPGs in regulation of GF signaling. Correlating the interactions of HS structures with GFs observed in binding assays with their biological activities in cells is critical for establishing their structure-activity relationships. We assessed the ability of neoPGs to promote functional pairing between FGF2 and its cell surface receptor FGFR (Figure 5a). Cultured wild- 
type murine embryonic stem cells (WT-mESC) and HS-deficient mESCs, lacking the HS

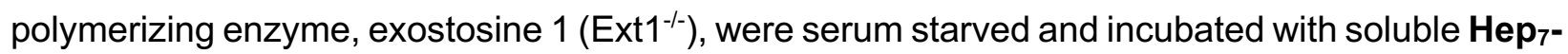
BSA or Hep $(0.25-5 \mu \mathrm{g} / \mathrm{mL})$. The mESCs were stimulated with and without soluble FGF2 (25 $\mathrm{ng} / \mathrm{mL}$ ) and probed for ERK phosphorylation (Phos-ERK) via Western blot analysis as a readout for FGFR activation and MAPK signaling (Figure 5b). Hep 7 -BSA enhanced FGF2-mediated FGFR signaling compared to equivalent concentrations of Hep, inferring an increased capacity of the multivalent neoPG to form a stable ternary complex compared to Hep alone. We also tested the impact of valency using $\operatorname{Hep}_{\mathbf{x}}-\mathrm{BSA}(\mathrm{x}=1,2$, or 4 , normalized to total Hep concentration) and observed increased ERK phosphorylation response with increasing conjugate valency (Figure 5c), consistent with a valency-dependent FGF2 binding observed for immobilized Hep -BSA $^{-B}$ (Figure 3b). These findings demonstrate the importance of the overall macromolecular architecture of the neoPGs on signaling and the ability to correlate binding data obtained from ELISA assays to biological activity in cells.

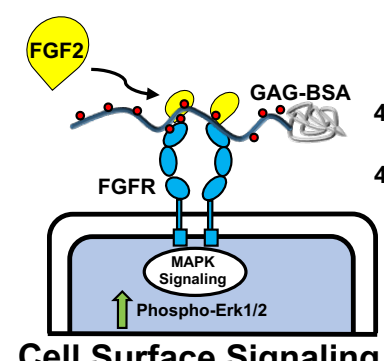

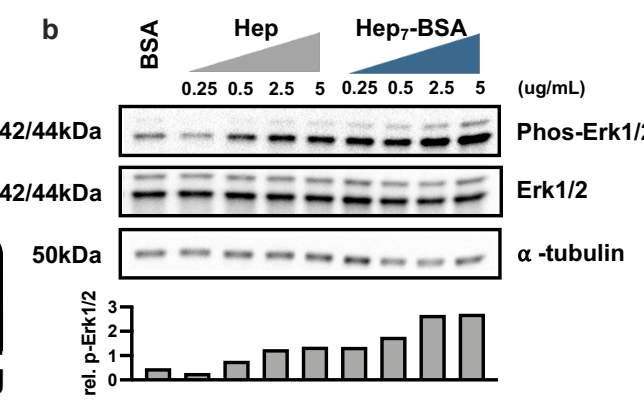

Figure 5. neoPGs promote FGF2 signaling in $\mathrm{HS}$ deficient mouse embryonic stem cells (Ext1 ${ }^{-/-}$ $\mathrm{mESCs}$ ). a) Cartoon depiction of FGF2 stimulation assay in Ext1 $1^{-/-} \mathrm{mESCs}$ in the presence of Hep $_{\mathrm{x}}-\mathrm{BSA}$. b) The cells were stimulated with FGF2 $(25 \mathrm{ng} / \mathrm{mL})$ in the presence of increasing concentrations of soluble Hep or Hep - -BSA conjugate. Cell lysates were assesed for Erk1/2 phosphorylation after stimulation via western blot and densitometry analysis. $\alpha$-Tubulin was used as a loading control. The data are representative examples of at least 2 independent biological replicates. c) $\mathrm{Ext}^{---} \mathrm{mESC}$ were stimulated with FGF2 $(25 \mathrm{ng} / \mathrm{mL})$ in the presence of Hep $\mathrm{H}_{\mathbf{x}}-\mathrm{BSA}$ with increasing numbers of Hep chains $(x=1,2,4)$ normalized to $5 \mu \mathrm{g} / \mathrm{mL}$ heparin concentration to assess valency effects on MAPK activation. 


\section{Conclusion}

In this report, we outline an efficient and tunable method for generating neoPG conjugates by merging biologically-derived or bioengineered GAG polysaccharides and cyclooctyne-modified BSA protein via a novel bifunctional fluorogenic linker. The method was applicable to all members of the GAG family, including rHS polysaccharides produced in cells with genetically engineered HS biosynthesis. The conjugation process generates a fluorescent signal, which can be used to monitor the progress of the reaction and determine the overall composition of the resulting neoPGs. The reagents were arrayed in 96-well plates to evaluate the ligand specificity of GAGbinding proteins in a convenient ELISA format. Compared to traditional immobilization strategies based on electrostatic adsorption, the conjugation of GAGs to BSA via their reducing-ends provides impartial surface presentation, which enabled analysis of substrate specificity for GAGremodeling lyase and sulfatase enzymes. The neoPGs can also be deployed as soluble probes to confirm their growth factor binding activity in cell signaling assays. With the rapid advancements in precision engineering of cellular glycosylation pathways, these reagents are poised to provide a powerful complement to existing array platforms based on synthetically defined oligosaccharides and contribute a more complete understanding of structure-activity relationships in GAG-protein binding interactions.

\section{Methods and Materials}

\section{3-azido- coumarin-7-sulfonyl fluoride (ACS-F) synthesis}

To a $4 \mathrm{~mL}$ vial containing 3-azido-7-hydroxycoumarin (100 mg, $0.49 \mathrm{mmol}, 1.0$ eq.) and 4[(Acetylamino)phenyl]imidodisulfuryl difluoride (AISF, $186 \mathrm{mg}, 0.58 \mathrm{mmol}, 1.2$ equiv.) was added anhydrous DMSO (1.6 mL) followed by 1,8-diazabicyclo [5.4.0]undec-7-ene (DBU, $161 \mu \mathrm{L}, 1.08$ mmol, 2.2 equiv.) over a period of 60 seconds. The reaction mixture stirred at ambient temperature for $1 \mathrm{~h}$, diluted with ethyl acetate and washed with $0.5 \mathrm{~N} \mathrm{HCl}(2 \mathrm{x})$ and once with brine. Combined organic fraction was dried with anhydrous magnesium sulfate and concentrated 
under reduced pressure. The crude residue was purified by silica gel flash chromatography $(0 \rightarrow$ $40 \% \mathrm{EtOAc} / \mathrm{Hex}$ with elution at $\sim 15 \% \mathrm{EtOAc} / \mathrm{Hex}$ ) to afford the product (35 $\mathrm{mg}, 28 \%$ yield) as a crystalline clear solid. ${ }^{1} \mathrm{H}$ NMR $\left(500 \mathrm{MHz}, \mathrm{CDCl}_{3}\right) \delta 7.54(\mathrm{~d}, J=8.6 \mathrm{~Hz}, 1 \mathrm{H}), 7.37(\mathrm{~d}, J=2.3 \mathrm{~Hz}$, $1 \mathrm{H}$ ), 7.30 (ddd, $J=8.6,2.4,0.7 \mathrm{~Hz}, 1 \mathrm{H}$ ), 7.21 (s, 1H). ${ }^{13} \mathrm{C} \mathrm{NMR}\left(126 \mathrm{MHz}^{\mathrm{C}} \mathrm{CDCl}_{3}\right) \delta 156.47$, 151.52, 149.88, 128.93, 127.91, 124.00, 119.78, 118.10, 110.09 ppm. ${ }^{19} \mathrm{~F}$ NMR: (282 MHz, $\left.\mathrm{CDCl}_{3}\right) \delta 39.0(\mathrm{~s}, 1 \mathrm{~F})$. Absorbance and fluorescence spectra were obtained by analyzing unreacted and Heparin-conjugated to ACS-F by absorbance scan pedestal analysis on a Nanodrop 2000c or fluorescence excitation and emission scan on a fluorimeter, respectively.

\section{GAG conjugation to ACS-F}

Commercial GAGs including heparin (20 mg, Iduron, Macclesfield SK10 4TG, UK), TEGA recombinant HS (rHS), or biologically-sourced GAGs were transferred to a PCR tube and dissolved in $90 \mu \mathrm{L}$ of $1 \mathrm{M}$ urea, $1 \mathrm{M}$ sodium acetate, $\mathrm{pH} 4.5$ buffer. To this solution was added 10 $\mu \mathrm{L}$ of a $1.15 \mathrm{M}$ n-methylaminooxy-propylamine linker ${ }^{34}$ (11.5 $\mu$ moles). Reducing end conjugation proceeded at $50^{\circ} \mathrm{C}$ for $24-48 \mathrm{~h}$. The reaction was quenched with $200 \mu \mathrm{L}$ of $2 \mathrm{M}$ Tris- $\mathrm{HCl}, \mathrm{pH} 8.1$ and GAG-amine was purified by PD-10 column, followed by concentration and removal of excess linker using $3 \mathrm{kDa}$ molecular weight spin filters as per manufacturer's instructions (Amicon, Millipore Sigma, St. Louis, MO). To $400 \mu \mathrm{L}$ of recovered GAG-amine was added $200 \mu \mathrm{L}$ of 100 mM sodium phosphate, pH 8.0 and $600 \mu \mathrm{L}$ DMSO. ACSF (38 mg, 133 umoles) was dissolved in $400 \mu \mathrm{L}$ DMSO and transferred to the GAG-amine solution. Sulfonyl fluoride exchange (SuFEx) proceeded at ambient temperature, shaking for $24 \mathrm{~h}$. The reaction was diluted with $900 \mu \mathrm{L}$ water and similarly purified over PD-10 column with elutions collected in a CoStar clear 96-well plate and analyzed by microplate absorbance at $326 \mathrm{~nm}$ to visualize ACS-GAG and excess ACS-F fractions. ACS-GAG fractions were pooled and similarly concentrated by $3 \mathrm{kDa}$ spin filtration, followed by lyophilization.

\section{BCN-BSA synthesis}

To a $1.5 \mathrm{~mL}$ microcentrifuge tube (Fisher scientific, Cat. No. 05408129) was added $1 \mathrm{~mL}$ of 100 $\mathrm{mM}$ sodium phosphate buffer, pH 8.0, $10 \mathrm{mg}$ BSA (VWR, Cat. No. 0332-25G), and 78.1 $\mu \mathrm{L}$ of a $10 \mathrm{mg} / \mathrm{mL}$ (1R,8S,9s)-Bicyclo[6.1.0]non-4-yn-9-ylmethyl N-succinimidyl carbonate (BCN, 17 eq.) (Sigma Aldrich, Cat. No. 744867-10MG) and stirred at $4^{\circ} \mathrm{C}$ for $16 \mathrm{~h}$. The reaction was dialyzed against MilliQ water in 25 kDa molecular weight cut-off dialysis tubing (Spectra, Cat No. 132126), for 48 hours, replacing water after 24 hours. Lyophilization of the dialyzed product affords $11 \mathrm{mg}$ of the product (quantitative yield). MALDI-TOF MS analysis indicates the modified BSA protein has a molecular weight of about 69,689 daltons compared a starting mass of 66,808 daltons for 
unmodified BSA. Each additional BCN adds 177.3 daltons, a difference of 3,259 daltons indicates approximately $16 \mathrm{BCN} / \mathrm{BSA}$.

\section{ACS-GAG conjugation to BCN-BSA}

To the wells of a black, clear-bottom CoStar 96-well plate were added either $200 \mu \mathrm{L}$ PBS, $50 \mu \mathrm{L}$ of $1 \mathrm{mM}$ ACS-F (50 nmoles), $50 \mu \mathrm{L}$ of $1 \mathrm{mM}$ ACS-GAG (50 nmoles), $100 \mu \mathrm{L} \mathrm{BCN-BSA}(0.5 \mathrm{mg} / \mathrm{mL}$ in water, 0.9 nmoles BSA and 8 nmoles BCN), $50 \mu \mathrm{L}$ ACS-F + $100 \mu \mathrm{L}$ BCN-BSA, or $50 \mu \mathrm{L}$ ACS$\mathrm{GAG}+100 \mu \mathrm{L} B C N-B S A$. Each well was brought up to a final volume of $200 \mu \mathrm{L}$ with PBS. Using a microplate spectrophotometer, kinetic fluorescence readings were collected with Ex. $393 \mathrm{~nm} /$ Em. $477 \mathrm{~nm}$ at various time points initially after addition of all reagents to 24-48 h. Post-incubation at ambient temperature for $26 \mathrm{~h}$, wells containing neoPG (GAG-BSA) or TCS-BSA (triazole) were filtered ( $5 \times 500 \mu \mathrm{L}$ water) through a $30 \mathrm{kDa}$ molecular weight spin filter to remove unreacted GAG and ACS-F. The recovered $40 \mu \mathrm{L}$ of neoPG or TCS-BSA was transferred into separate PCR tubes and water was added to a final concentration of $200 \mathrm{ug} / \mathrm{mL}$ BSA assuming $96 \%$ BSA recovery based on manufacturers data sheet and confirmed by BCA assay. The TCS-BSA and neoPG samples were further diluted for adsorption onto 96-well plates for binding assays.

\section{6-well ELISA binding assays}

neoPGs were diluted into $1 X$ Dulbecco's phosphate buffered saline $\mathrm{w} / \mathrm{Ca}^{2+}$ and $\mathrm{Mg}^{2+}(\mathrm{PBS})$ and adsorbed to a Greiner microplate high-binding clear-bottom 96-well plate (100 ng/well, $100 \mu \mathrm{L}$ final volume per well). Conjugates were adsorbed for $16 \mathrm{~h}$ at $4^{\circ} \mathrm{C}$. Post-adsorption, wells were washed three times with PBS, blocked with $100 \mu \mathrm{L}$ per well of $2 \%$ BSA in PBS for $1 \mathrm{~h}$ at ambient temperature, and washed again three times with PBS. Growth factors (GFs) and antibodies were diluted to final concentrations in 1\% BSA/PBS following manufacturer instructions or otherwise noted and added to the wells in triplicate. A triplicate set of control wells were not incubated with GAG-binding proteins. Binding proteins incubated for $2 \mathrm{~h}$ at ambient temperature. Wells were then washed three times with PBS, then incubated with a respective antibody precomplexed with an HRP-conjugated secondary antibody as necessary. For a precomplex, primary and secondary antibodies or binding proteins and their antibodies were combined in $1.5 \mathrm{~mL}$ Eppendorf tubes in $200 \mu \mathrm{L}$ of $1 \%$ BSA/PBS for 30 mins on ice prior to diluting to the final calculated concentration. Wells were incubated with the antibody precomplex for $1.5 \mathrm{~h}$ at ambient temperature, washed three times with PBS, and visualized with $100 \mu \mathrm{L}$ of TMB substrate (Invitrogen, 00-4201-56) with resulting colorimetric product measured on a SpectraMax i3x plate reader under a kinetic cycle with $370 \mathrm{~nm}$ absorbance (10 min total with 30 second increments). 
For enzymatic treatments including heparinase, chondroitinase $A B C$, hyaluronidase, keratanase II, and 6-O-endosulfatase 1 (HSulf-1), the neoPG immobilized plates were similarly blocked and washed with PBS as above followed by incubation in reaction buffer with or without enzyme present at $37^{\circ} \mathrm{C}$ for $16 \mathrm{~h}$. Post-enzymatic treatment was followed by three PBS washes and similar protein binding procedures as described above. For Sulf-1 enzyme purification, A375 KDM2B ${ }^{-/-}$ cells, kindly provided by Dr. Jeffrey Esko (UCSD), were cultured in OptiMEM for 3-5 days, conditioned media was collected and filtered through a $50 \mathrm{kDa}$ cut-off filter, total protein quantified by BCA assay, and presence of HSulf-1 validated by Western blot analysis and anti-Sulf1 detection. No detectable heparin lyase activity was present in conditioned media.

For biotin-PEG ${ }_{11}$-azide analyses, $\mathrm{BCN}-\mathrm{BSA}$ and $\mathrm{Hep}_{7}-\mathrm{BSA}$ were immobilized onto high-binding 96-well plates in the presence of varying equivalents of the biotin-azide reagent compared to total BCN per BSA (with 17 BCN/BSA, 0.1 eq = 1.7 biotin- EEG $_{11}$-azide per BSA and 1 eq = 17 biotin$\mathrm{PEG}_{11}$-azide per $\mathrm{BSA}$ ). To quantify neoPG immobilization efficiency, 0.5 eq of biotin-PEG ${ }_{11}$-azide was utilized in the immobilization assay to account for reacted $\mathrm{BCN}$ molecules that were no longer available. Post-immobilization at $4^{\circ} \mathrm{C}$ for $16 \mathrm{~h}$, wells were washed three times with PBS, blocked with $2 \%$ BSA/PBS, and incubated with HRP-conjugated streptavidin for $1.5 \mathrm{~h}$ at ambient temperature. Colorimetric analysis of streptavidin binding was conducted similarly to above binding analyses using a kinetic cycle of $370 \mathrm{~nm}$ absorbance readings.

Cell surface FGF receptor stimulation assay: FGF2 stimulation and western blotting was performed as detailed previously by the Godula lab. ${ }^{34}$ Briefly, mouse embryonic stem cells with endogenous HS production knocked out $\left(\mathrm{Ext}^{-1^{--}}\right)$were cultured in 6 -well plates treated with $0.1 \%$ gelatin before being serum starved for $20 \mathrm{~h}$ in mESC growth medium lacking FBS. Cells were then treated with $25 \mathrm{ng} / \mathrm{mL}$ recombinant human basic FGF (Peprotech) in serum-free medium with heparin, BSA, or $\mathrm{Hep}_{7}$-BSA conjugates $(5 \mu \mathrm{g} / \mathrm{mL})$ for a duration of $15 \mathrm{~min}$ at $37^{\circ} \mathrm{C}, 5 \% \mathrm{CO} 2$. The cells were then immediately chilled and lysed using a 1X RIPA lysis buffer supplemented with PMSF (1 mM) and $1 \mathrm{X}$ protease/phosphatase inhibitor cocktail. Cell lysates were analyzed by BCA assay to determine total protein concentration. $10 \mu \mathrm{g}$ total protein from each sample was resolved on a $10 \%$ SDS-PAGE gel and transferred to a PVDF membrane for blotting. The membrane was blocked with 5\% BSA in TBS supplemented with 0.1\% Tween-20 (TBST) for a minimum of $1 \mathrm{~h}$ at ambient temperature prior to staining (overnight, $4^{\circ} \mathrm{C}$ ) with anti-phospho Erk, anti-total Erk, or anti-alpha tubulin $(1: 1250,1: 1250,1: 25000$ respectively in 5\% BSA). After three TBST washes the membrane was incubated with HRP-conjugated secondary antibodies (1:2,000 anti-rabbit HRP and 1:10000 anti-mouse HRP, respectively) for approximately $1.5 \mathrm{~h}$ at ambient temperature. 
Following a series of TBST washes the blots were visualized using Luminata Forte HRP detection reagent and imaged on a gel scanner (BioRad) for chemiluminescence. For sequential staining, blots were washed in TBST, stripped using Restore PLUS Western blot stripping buffer, washed again in TBST and blocked in 5\% BSA for at least $1 \mathrm{~h}$ at ambient temperature before further staining. Images were analyzed using ImageJ, with phospho-Erk1/2 and total-Erk1/2 normalized to alpha tubulin, then phospho-Erk was normalized to total-Erk. Lastly, the levels of relative Erk phosphorylation were determined by setting the phosphorylation of Erk in samples containg Ext $1^{-}$ I- mESCs without FGF2 or neoPG to equal 1.

\section{Acknowledgements}

We thank Dr Jeffrey D. Esko (UC San Diego) for helpful discussions and for generously providing reagents. This work was supported by the NHLBI K12 Career Development in Glycosciences program K12HL141956 to R.N.P. This work was supported in part by the NIH Director's New Innovator Award (NICHD: 1DP2HD087954-01). KG was supported by the Alfred P. Sloan Foundation (FG-2017-9094) and the Research Corporation for Science Advancement via the Cottrell Scholar Award (grant \#24119).

\section{Author Contributions}

R.N.P., K.G., and P.L.S.M.G. conceived, initiated, and coordinated the project. R.N.P., J.L.F, S.P., B.T., D.K., and L.L. designed and performed the experimental work. B.E.T. and C.A.G. provided rHS samples from TEGA Therapeutics. R.N.P., J.L.F., and K.G. wrote the manuscript. All authors discussed the experiments and results, read, and approved the manuscript.

\section{Conflicts of Interest}

C.A.G. and B.E.T. are employees of TEGA Therapeutics. 


\title{
References
}

\begin{abstract}
${ }^{1}$ Zhang, F., Zheng, L., Cheng, S., Peng, Y., Fu, L., Zhang, X., Linhardt, R.J. Comparison of the Interactions of Different Growth Factors and Glycosaminoglycans. Molecules. 2019, 24(18), 3360. DOI: $10.3390 /$ molecules 24183360 .
\end{abstract}

${ }^{2}$ Mizumoto, S., Yamada, S., Sugahara, K. Molecular Interactions between Chondroitin-Dermatan Sulfate and Growth Factors/Receptors/Matrix Proteins. Curr. Opin. Struct. Biol. 2015, 34, 35-42. DOI: 10.1016/j.sbi.2015.06.004.

${ }^{3}$ Matsuo, I., Kimura-Yoshida, C. Extracellular Modulation of Fibroblast Growth Factor Signaling through Heparan Sulfate Proteoglycans in Mammalian Development. Curr. Opin. Genet. Dev. 2013 23(4), 399407. DOI: 10.1016/j.gde.2013.02.004.

4 Townley, R.A., Bülow, H.E. Deciphering Functional Glycosaminoglycan Motifs in Development. Curr. Opin. Struct. Biol. 2018 50, 144-154. DOI: 10.1016/j.sbi.2018.03.011.

${ }^{5}$ Nakato, H., Li, J.P. Functions of Heparan Sulfate Proteoglycans in Development: Insights From Drosophila Models. Int. Rev. Cell Mol. Biol. 2016 325, 275-93. DOI: 10.1016/bs.ircmb.2016.02.008.

${ }^{6}$ Raghunathan, R., Hogan, J.D., Labadorf, A., Myers, R.H., Zaia, J. A Glycomics and Proteomics Study of Aging and Parkinson's Disease in Human Brain. Sci. Rep. 2020 10(1), 12804. DOI: 10.1038/s41598-02069480-3.

7 Taylor, K.R., Gallo, R.L. Glycosaminoglycans and their Proteoglycans: Host-associated Molecular Patterns for Initiation and Modulation of Inflammation. FASEB J. 2006 20(1), 9-22. DOI: 10.1096/fj.054682rev.

${ }^{8}$ Gonzalez-Gil, A., Porell, R.N., Fernandes, S.M., Wei, Y., Yu, H., Carroll, D.J., McBride, R., Paulson. J.C., Tiemeyer, M., Aoki, K., Bochner, B.S., Schnaar, R.L. Sialylated Keratan Sulfate Proteoglycans are Siglec-8 Ligands in Human Airways. Glycobiology. 2018 28(10), 786-801. DOI: 10.1093/glycob/cwy057.

${ }^{9}$ Shukla, D., Liu, J., Blaiklock, P., Shworak, N.W., Bai, X., Esko, J.D., Cohen, G.H., Eisenberg, R.J., Rosenberg, R.D., Spear, P.G. A Novel Role for 3-O-Sulfated Heparan Sulfate in Herpes Simplex Virus 1 Entry. Cell. 1999 99(1), 13-22. DOI: 10.1016/s0092-8674(00)80058-6.

${ }^{10}$ Clausen, T.M., Sandoval, D.R., Spliid, C.B., Pihl, J., Perrett, H.R., Painter, C.D., Narayanan, A., Majowicz, S.A., Kwong, E.M., McVicar, R.N., Thacker, B.E., Glass, C.A., Yang, Z., Torres, J.L., Golden, G.J., Bartels, P.L., Porell, R.N., Garretson, A.F., Laubach, L., Feldman, J., Yin, X., Pu, Y., Hauser, B.M., Caradonna, T.M., Kellman, B.P., Martino, C., Gordts, P.L.S.M., Chanda, S.K., Schmidt, A.G., Godula, K., Leibel, S.L., Jose, J., Corbett, K.D., Ward, A.B., Carlin, A.F., Esko, J.D. SARS-CoV-2 Infection Depends on Cellular Heparan Sulfate and ACE2. Cell. 2020 183(4), 1043-1057.e15. DOI:

10.1016/j.cell.2020.09.033.

${ }^{11}$ Kjellén L, Lindahl U. Specificity of glycosaminoglycan-protein interactions. Curr Opin Struct Biol. 2018 50, 101-108. DOI: 10.1016/j.sbi.2017.12.011.

12 Zong C, Venot A, Li X, Lu W, Xiao W, Wilkes JL, Salanga CL, Handel TM, Wang L, Wolfert MA, Boons GJ. Heparan Sulfate Microarray Reveals That Heparan Sulfate-Protein Binding Exhibits Different Ligand Requirements. J Am Chem Soc. 2017 139(28), 9534-9543. DOI: 10.1021/jacs.7b01399.

${ }^{13}$ Wang D, Liu S, Trummer BJ, Deng C, Wang A. Carbohydrate microarrays for the recognition of crossreactive molecular markers of microbes and host cells. Nat Biotechnol. 2002 20(3), 275-81. DOI:

10.1038/nbt0302-275. 


\begin{abstract}
${ }^{14}$ Houseman BT, Mrksich M. Carbohydrate arrays for the evaluation of protein binding and enzymatic modification. Chem Biol. 2002 9(4):443-54. DOI: 10.1016/s1074-5521(02)00124-2.
\end{abstract}

${ }^{15}$ Fukui S, Feizi T, Galustian C, Lawson AM, Chai W. Oligosaccharide microarrays for high-throughput detection and specificity assignments of carbohydrate-protein interactions. Nat Biotechnol. 2002 20(10), 1011-7. DOI: $10.1038 / \mathrm{nbt735.}$

${ }^{16}$ Mende M, Bordoni V, Tsouka A, Loeffler FF, Delbianco M, Seeberger PH. Multivalent glycan arrays. Faraday Discuss. 2019 219(0), 9-32. DOI: 10.1039/c9fd00080a.

17 Smith DF, Song X, Cummings RD. Use of glycan microarrays to explore specificity of glycan-binding proteins. Methods Enzymol. 2010 480, 417-44. DOI: 10.1016/S0076-6879(10)80033-3.

${ }^{18}$ de Paz JL, Noti C, Seeberger PH. Microarrays of synthetic heparin oligosaccharides. J Am Chem Soc. 2006 128(9), 2766-7. DOI: 10.1021/ja057584v.

19 Tully SE, Rawat M, Hsieh-Wilson LC. Discovery of a TNF-alpha antagonist using chondroitin sulfate microarrays. J Am Chem Soc. 2006 128(24), 7740-1. DOI: 10.1021/ja061906t.

${ }^{20}$ Pomin VH, Wang X. Synthetic Oligosaccharide Libraries and Microarray Technology: A Powerful Combination for the Success of Current Glycosaminoglycan Interactomics. Chem. Med. Chem. 2018 13(7), 648-661. DOI: $10.1002 / \mathrm{cmdc} .201700620$.

${ }^{21}$ Zong C, Venot A, Li X, Lu W, Xiao W, Wilkes JL, Salanga CL, Handel TM, Wang L, Wolfert MA, Boons GJ. Heparan Sulfate Microarray Reveals That Heparan Sulfate-Protein Binding Exhibits Different Ligand Requirements. J Am Chem Soc. 2017 139(28), 9534-9543. DOI: 10.1021/jacs.7b01399.

22 Zhang X, Lin L, Huang H, Linhardt RJ. Chemoenzymatic Synthesis of Glycosaminoglycans. Acc Chem Res. 2020 53(2), 335-346. DOI: 10.1021/acs.accounts.9b00420.

${ }^{23}$ Horton M, Su G, Yi L, Wang Z, Xu Y, Pagadala V, Zhang F, Zaharoff DA, Pearce K, Linhardt RJ, Liu J. Construction of heparan sulfate microarray for investigating the binding of specific saccharide sequences to proteins. Glycobiology. 2021 31(3), 188-199. DOI: 10.1093/glycob/cwaa068.

${ }^{24}$ Shipp EL, Hsieh-Wilson LC. Profiling the sulfation specificities of glycosaminoglycan interactions with growth factors and chemotactic proteins using microarrays. Chem Biol. 2007 14(2), 195-208. DOI: 10.1016/j.chembiol.2006.12.009.

${ }^{25}$ Chen YH, Narimatsu Y, Clausen TM, Gomes C, Karlsson R, Steentoft C, Spliid CB, Gustavsson T, Salanti A, Persson A, Malmström A, Willén D, Ellervik U, Bennett EP, Mao Y, Clausen H, Yang Z. The GAGOme: a cell-based library of displayed glycosaminoglycans. Nat Methods. 2018 15(11), 881-888. DOI: 10.1038/s41592-018-0086-z.

${ }^{26}$ Qiu H, Shi S, Yue J, Xin M, Nairn AV, Lin L, Liu X, Li G, Archer-Hartmann SA, Dela Rosa M, Galizzi M, Wang S, Zhang F, Azadi P, van Kuppevelt TH, Cardoso WV, Kimata K, Ai X, Moremen KW, Esko JD, Linhardt RJ, Wang L. A mutant-cell library for systematic analysis of heparan sulfate structure-function relationships. Nat Methods. 2018 15(11), 889-899. DOI: 10.1038/s41592-018-0189-6.

${ }^{27}$ Rogers CJ, Hsieh-Wilson LC. Microarray method for the rapid detection of glycosaminoglycan-protein interactions. Methods Mol Biol. 2012 808, 321-336. DOI: 10.1007/978-1-61779-373-8_22.

${ }^{28}$ Hof DJ, Versteeg EMM, van de Lest CHA, Daamen WF, van Kuppevelt TH. A versatile salt-based method to immobilize glycosaminoglycans and create growth factor gradients. Glycoconj J. 2019 36(3), 227-236. DOI: 10.1007/s10719-019-09872-4. 
${ }^{29}$ Takada W, Fukushima M, Pothacharoen P, Kongtawelert P, Sugahara K. A sulfated glycosaminoglycan array for molecular interactions between glycosaminoglycans and growth factors or anti-glycosaminoglycan antibodies. Anal Biochem. 2013 435(2), 123-30. DOI: 10.1016/j.ab.2013.01.004.

${ }^{30}$ Gray CJ, Sánchez-Ruíz A, Šardzíková I, Ahmed YA, Miller RL, Reyes Martinez JE, Pallister E, Huang K, Both P, Hartmann M, Roberts HN, Šardzík R, Mandal S, Turnbull JE, Eyers CE, Flitsch SL. Label-Free Discovery Array Platform for the Characterization of Glycan Binding Proteins and Glycoproteins. Anal Chem. 2017 89(8), 4444-4451. DOI: 10.1021/acs.analchem.6b04122.

${ }^{31}$ Dimitrellos V, Lamari FN, Militsopoulou M, Kanakis I, Karamanos NK. Capillary electrophoresis and enzyme solid phase assay for examining the purity of a synthetic heparin proteoglycan-like conjugate and identifying binding to basic fibroblast growth factor. Biomed Chromatogr. 2003 17(1), 42-7. DOI:

10.1002/bmc.208.

${ }^{32}$ Agard, N.J., Prescher, J.A., Bertozzi, C.R. A Strain-Promoted [3+2] Azide-Alkyne Cycloaddition for Covalent Modification of Biomolecules in Living Systems. J. Am. Chem. Soc.2004 126(46), 15046-15047. DOI: 10.1021/ja044996f.

${ }^{33}$ Dong J, Krasnova L, Finn MG, Sharpless KB. Sulfur(VI) fluoride exchange (SuFEx): another good reaction for click chemistry. Angew Chem Int Ed Engl. 2014 53(36), 9430-48. DOI:

10.1002/anie.201309399.

${ }^{34}$ Huang ML, Smith RA, Trieger GW, Godula K. Glycocalyx remodeling with proteoglycan mimetics promotes neural specification in embryonic stem cells. J Am Chem Soc. 2014 Jul 30;136(30):10565-8. doi: 10.1021/ja505012a.

${ }^{35}$ Lees A, Sen G, LopezAcosta A. Versatile and efficient synthesis of protein-polysaccharide conjugate vaccines using aminooxy reagents and oxime chemistry. Vaccine. 2006 24(6), 716-29. DOI:

10.1016/j.vaccine.2005.08.096.

${ }^{36}$ Lallana E, Fernandez-Megia E, Riguera R. Surpassing the use of copper in the click functionalization of polymeric nanostructures: a strain-promoted approach. J Am Chem Soc. 2009 131(16), 5748-50. DOI: 10.1021/ja8100243.

${ }^{37}$ Montgomery, R.I., Lidholt, K., Flay, N.W., Liang, J., Vertel, B., Lindahl, U., Esko, J.D. Stable heparinproducing cell lines derived from the Furth murine mastocytoma. Proc Natl Acd Sci U S A. 1992, 90(23). 11327-11331. DOI: 10.1073/pnas.89.23.11327.

${ }^{38}$ Rusnati M, Coltrini D, Caccia P, Dell'Era P, Zoppetti G, Oreste P, Valsasina B, Presta M. Distinct role of 2-O-, N-, and 6-O-sulfate groups of heparin in the formation of the ternary complex with basic fibroblast growth factor and soluble FGF receptor-1. Biochem Biophys Res Commun. 1994 203(1), 450-8. DOI: 10.1006/bbrc.1994.2203.

${ }^{39}$ Smith RAA, Murali S, Rai B, Lu X, Lim ZXH, Lee JJL, Nurcombe V, Cool SM. Minimum structural requirements for BMP-2-binding of heparin oligosaccharides. Biomaterials. 2018 184, 41-55. DOI: 10.1016/j.biomaterials.2018.08.056.

${ }^{40}$ Zhao W, McCallum SA, Xiao Z, Zhang F, Linhardt RJ. Binding affinities of vascular endothelial growth factor (VEGF) for heparin-derived oligosaccharides. Biosci Rep. 2012 32(1):71-81. DOI:

10.1042/BSR20110077.

${ }^{41}$ Uchimura, K.; Morimoto-Tomita, M.; Bistrup, A.; Li, J.; Lyon, M.; Gallagher, J.; Werb, Z.; Rosen, S. D. HSulf-2, an Extracellular Endoglucosamine-6-Sulfatase, Selectively Mobilizes Heparin-Bound Growth Factors and Chemokines: Effects on VEGF, FGF-1, and SDF-1. BMC Biochem. 2006, 7 (1), 2. DOI: 10.1186/1471-2091-7-2. 
${ }^{42}$ Lamanna, W. C.; Frese, M. A.; Balleininger, M.; Dierks, T. Sulf Loss Influences N-, 2-O-, and 6-OSulfation of Multiple Heparan Sulfate Proteoglycans and Modulates Fibroblast Growth Factor Signaling. J. Biol. Chem. 2008, 283 (41), 27724-27735. DOI: 10.1074/jbc.M802130200.

${ }^{43}$ Hossain, M. M.; Hosono-Fukao, T.; Tang, R.; Sugaya, N.; van Kuppevelt, T. H.; Jenniskens, G. J.; Kimata, K.; Rosen, S. D.; Uchimura, K. Direct Detection of HSulf-1 and HSulf-2 Activities on Extracellular Heparan Sulfate and Their Inhibition by PI-88. Glycobiology 2010, 20 (2), 175-186. DOI: 10.1093/glycob/cwp159.

${ }^{44}$ Seffouh, A.; Milz, F.; Przybylski, C.; Laguri, C.; Oosterhof, A.; Bourcier, S.; Sadir, R.; Dutkowski, E.; Daniel, R.; Van Kuppevelt, T. H.; et al. HSulf Sulfatases Catalyze Processive and Oriented 6-ODesulfation of Heparan Sulfate That Differentially Regulates Fibroblast Growth Factor Activity. FASEB J. 2013, 27 (6), 2431-2439. DOI: 10.1096/fj.12-226373.

${ }^{45}$ Morimoto-Tomita, M., Uchimura, K., Werb, Z., Hemmerich, S. \& Rosen, S. D. Cloning and Characterization of Two Extracellular Heparin-degrading Endosulfatases in Mice and Humans. J. Biol. Chem. 2002 277, 49175-49185. DOI: 10.1074/jbc.M205131200.

${ }^{46}$ El Masri, R.; Seffouh, A.; Lortat-Jacob, H.; Vivès, R. R. The “in and out” of Glucosamine 6-O-Sulfation: The 6th Sense of Heparan Sulfate. Glycoconj. J. 2016, 1-14. DOI: 10.1007/s10719-016-9736-5. 